\title{
Bacteria Regulate Intestinal Epithelial Cell Differentiation Factors Both In Vitro and In Vivo
}

\author{
Svetlana Becker ${ }^{1,2}$, Tobias A. Oelschlaeger ${ }^{3}$, Andy Wullaert ${ }^{4}$, Manolis Pasparakis ${ }^{4,5}$, Jan Wehkamp ${ }^{1,2,6}$, \\ Eduard F. Stange ${ }^{6}$, Michael Gersemann ${ }^{1,2,6 *}$
}

1 Dr. Margarete Fischer-Bosch Institute for Clinical Pharmacology, Stuttgart, Germany, 2 University of Tübingen, Tübingen, Germany, $\mathbf{3}$ Institute for Molecular Biology of Infection, University of Würzburg, Würzburg, Germany, 4 Institute for Genetics, University of Cologne, Cologne, Germany, 5 EMBL Mouse Biology Unit, Monterotondo, Italy, 6 Department of Internal Medicine I, Robert Bosch Hospital, Stuttgart, Germany

\begin{abstract}
Background: The human colon harbours a plethora of bacteria known to broadly impact on mucosal metabolism and function and thought to be involved in inflammatory bowel disease pathogenesis and colon cancer development. In this report, we investigated the effect of colonic bacteria on epithelial cell differentiation factors in vitro and in vivo. As key transcription factors we focused on Hes1, known to direct towards an absorptive cell fate, Hath1 and KLF4, which govern goblet cell.

Methods: Expression of the transcription factors Hes1, Hath1 and KLF4, the mucins Muc1 and Muc2 and the defensin HBD2 were measured by real-time PCR in LS174T cells following incubation with several heat-inactivated E. coli strains, including the probiotic E. coli Nissle 1917+/- flagellin, Lactobacilli and Bifidobacteria. For protein detection Western blot experiments and chamber-slide immunostaining were performed. Finally, mRNA and protein expression of these factors was evaluated in the colon of germfree vs. specific pathogen free vs. conventionalized mice and colonic goblet cells were counted.

Results: Expression of Hes1 and Hath1, and to a minor degree also of KLF4, was reduced by E. coli K-12 and E. coli Nissle 1917. In contrast, Muc1 and HBD2 expression were significantly enhanced, independent of the Notch signalling pathway. Probiotic E. coli Nissle 1917 regulated Hes1, Hath1, Muc1 and HBD2 through flagellin. In vivo experiments confirmed the observed in vitro effects of bacteria by a diminished colonic expression of Hath 1 and KLF4 in specific pathogen free and conventionalized mice as compared to germ free mice whereas the number of goblet cells was unchanged in these mice.
\end{abstract}

Conclusions: Intestinal bacteria influence the intestinal epithelial differentiation factors Hes1, Hath1 and KLF4, as well as Muc1 and HBD2, in vitro and in vivo. The induction of Muc1 and HBD2 seems to be triggered directly by bacteria and not by Notch.

Citation: Becker S, Oelschlaeger TA, Wullaert A, Pasparakis M, Wehkamp J, et al. (2013) Bacteria Regulate Intestinal Epithelial Cell Differentiation Factors Both In Vitro and In Vivo. PLoS ONE 8(2): e55620. doi:10.1371/journal.pone.0055620

Editor: Hang Thi Thu Nguyen, University of Auvergne, France

Received March 1, 2012; Accepted January 3, 2013; Published February 13, 2013

Copyright: (c) 2013 Becker et al. This is an open-access article distributed under the terms of the Creative Commons Attribution License, which permits unrestricted use, distribution, and reproduction in any medium, provided the original author and source are credited.

Funding: This work was supported by the Robert Bosch fundation and by Emmy Noether program of the Deutsche Forschungsgemeinschaft (DFG). The funders had no role in study design, data collection and analysis, decision to publish, or preparation of the manuscript.

Competing Interests: The authors have declared that no competing interests exist.

* E-mail: m.gersemann@kk-es.de

\section{Introduction}

The colon provides the most favorable conditions for intestinal microbiota and harbors, with approximately $10^{12}$ microorganisms per gram of intestinal content, the most densely populated and complex community of the human gastrointestinal tract $[1,2]$. During evolution a complex and intensive mutualistic relationship between bacteria and host has developed. The intestinal microflora influences the host in different ways by modulating the immune system, protecting against pathogen invasion and attachment, and contributing to digestion and nutritional uptake [3].

In a healthy gut the synergistic co-existence of intestinal microflora and the host is secured by an intact mucosal barrier. The barrier is provided by the intestinal epithelium, consisting of absorptive, goblet, Paneth and neuroendocrine cells, separating the intestinal wall from the luminal microbes. Goblet cells secrete mucins, e.g. Mucl and Muc2 as structural proteins of the protective mucus layer covering the whole gastrointestinal tract [4]. Moreover, epithelial cells produce broad-spectrum antimicrobial peptides, including defensins [5-8]. Once secreted, the small cationic defensins are fixed in the negatively charged mucus [9]. This mucus barrier is the first front of gut defence shielding the intestinal wall from luminal microbiota.

The intestinal epithelium differentiates from multipotent stem cells located at the bottom of the crypt and undergoes a rapid and continuous regeneration [10]. This process is regulated by a complex network of different differentiation signals. For example, the early determination of secretory versus absorptive cells is regulated by antagonistic interplay of the Notch target gene Hes 1 and the basic helix-loop-helix transcription factor Hathl. In progenitor cells expressing Hes1, Hathl gene expression is blocked, directing the cells to the absorptive fate. In contrast, in 
Table 1. Characteristics of the bacterial strains.

\begin{tabular}{|c|c|c|c|}
\hline Strain & Stereotype & Characteristics/Isolatetypes/Deletions* & Source \\
\hline E. coli Nissle 1917 (DSM 6601) & $\mathrm{O} 6: \mathrm{K} 5: \mathrm{H} 1$ & Apathogen, pharmaceutical strain & ACS \\
\hline EcN $\Delta$ fliA & & Sigma factor of flagella genes* & WÜR \\
\hline EcN $\Delta$ flic & & flagellin* & \\
\hline EcN $\Delta$ flgE & & hook* & \\
\hline EcN $\Delta$ fim & & Type 1 pili* & \\
\hline EcN $\Delta$ foc & & F1C pili* & \\
\hline $\mathrm{EcN} \Delta \operatorname{csg} B A$ & & Curli-negative* & \\
\hline E. coli K-12 & DSM 498 & Reference strain & DSMZ \\
\hline L. fermentum & PZ 1162 & Intestinal isolate & ACS \\
\hline L. acidophilus & PZ 1138 & Industrial probiotic strain & ACS (GR) \\
\hline B. longum (DSM 20219T) & PZ 1323 & Intestinal isolate & ACS \\
\hline B. breve & $\mathrm{Ha} / 14 \mathrm{c}$ & Intestinal isolate & ACS \\
\hline B. adolescentis TSD & PZ 4009 & Intestinal isolate & ACS \\
\hline B. vulgatus & DSM 1447 & Intestinal isolate & DSMZ \\
\hline E. coli DSM 17252 & & & SYM \\
\hline S2 G1: E. coli & Osp.:H- & Probiotic strain & \\
\hline \multicolumn{4}{|l|}{ Genotype $1 / 2$} \\
\hline S2 G2: E. coli & O 13.:H- & Probiotic strain & \\
\hline \multicolumn{4}{|l|}{ Genotype 3/10 } \\
\hline S2 G3: E. coli & Osp.:H- & Probiotic strain & \\
\hline \multicolumn{4}{|l|}{ Genotype 4/10 } \\
\hline $\begin{array}{l}\text { EcN...E. coli Nissle } 1917 . \\
\text { ACS: Ardeypharm collection of } \\
\text { WÜR: Collection of strains, Univ } \\
\text { DSMZ: German Collection of M } \\
\text { GR: Strain collection of G. Reut } \\
\text { SYM: SymbioPharm GmbH, Ger } \\
\text { doi:10.1371/journal.pone.00556 }\end{array}$ & $\begin{array}{l}\text { ha-Zentrale Gm } \\
\text { zburg. } \\
\text { and Cell cultu } \\
\text { osited by Mitus }\end{array}$ & $\begin{array}{l}\text {, Germany. } \\
\text { weig, Germany. } \\
\text { panese Collection of Microorganisms). }\end{array}$ & \\
\hline
\end{tabular}

progenitors with inactive Notch/Hes1 signaling, the Hathl gene can be transcriptionally activated and these cells transit to the secretory lineage $[11,12]$. The predetermined cells of the secretory line require additional signals for differentiation to specific cell types such as, for goblet cells, the zinc-finger transcription factor KLF4 [13].

Dysregulation of this regulatory network may lead to defective epithelial differentiation and finally to altered function of the mucosal barrier as shown in both forms of inflammatory bowel diseases (IBD), Grohn's disease (CD) and ulcerative colitis (UC) $[14,15]$. There is mounting evidence that the commensal intestinal microbiota plays a key role in the pathogenesis of IBD [16]. Among other evidence, this is underlined by the observation that patients with IBD have more mucosa-adherent bacteria, some of which are even found intracellularly [17,18]. Moreover, recent studies linked intestinal epithelial differentiation to IBD development. For instance, ileal CD is associated with defective Wnt mediated Paneth cell differentiation and consequently with a diminished production of the defensins HD5 and HD6 resulting in decreased mucosal antibacterial activity [19,20]. In active UC, defective Hathl expression $[21,22]$ is associated with a decreased number of mature goblet cells in the upper part of the colonic crypt [21]. As a consequence, mucin synthesis in active UC is defective leading to a diminished mucus layer [23,24]. In both cases, these epithelial differentiation defects may lead to invasion of the luminal bacteria into the mucosa where they could trigger inflammation. Additionally, there is evidence that bacteria could contribute to colon cancer development. For instance, animal models showed carcinogenic properties in some bacterial species

Table 2. Oligonucleotide primer pairs used for PCR measurements.

\begin{tabular}{|c|c|c|}
\hline Product & Forward primer $\left(5^{\prime}->3^{\prime}\right)$ & Reverse primer $\left(5^{\prime}->3^{\prime}\right)$ \\
\hline B-actin & GCCAACCGCGAGAAGATGA & CATCACGATGCCAGTGGTA \\
\hline Hath1 & CGAGAGAGCATCCCGTCTAC & TCCGGGGAATGTAGCAAATA \\
\hline KLF4 & CCCACACAGGTGAGAAACCT & ATGTGTAAGGCGAGGTGGTC \\
\hline Hes 1 & CTCTCTTCCCTCCGGACTCT & AGGCGCAATCCAATATGAAC \\
\hline Muc1 & AGACGTCAGCGTGAGTGATG & CAGCTGCCCGTAGTTCTITC \\
\hline Muc2 & ACCCGCACTATGTCACCTTC & GGGATCGCAGTGGTAGTTGT \\
\hline HBD2 & ATCAGCCATGAGGGTCTTGT & GAGACCACAGGTGCCAATTT \\
\hline mß-actin & GCTGAGAGGGAAATCGTGCGTG & CCAGGGAGGAAGAGGATGCGG \\
\hline Math1 & AGAGACCTTCCCGTCTACCC & CTGCAAAGTGGGAGTCAGC \\
\hline mHes1 & AGAGGCGAAGGGCAAGAATA & CGGAGGTGCTTCACAGTCAT \\
\hline mKLF4 & AGAGGAGCCCAAGCCAAAGAGG & CCACAGCCGTCCCAGTCACAGT \\
\hline mMuc1 & GAAGACCCCAGCTCCAACTA & GGAGCCTGACCTGAACTTGA \\
\hline mMuc2 & GTGTGGGACCTGACAATGTG & ACAACGAGGTAGGTGCCATC \\
\hline
\end{tabular}


$[25,26]$. Moreover, patients with colorectal cancer exhibit bacteria adhering to tumor tissue [27] and have indirect evidence of bacterial invasion $[28,29]$.

The aim of the present study was to elucidate whether and how bacteria regulate intestinal epithelial cell differentiation. The effects of microbiota on the expression of epithelial differentiation factors Hath1, KLF4 and Hes1, as well as the mucins Muc1, Muc2 and the defensin HBD2 were analysed in vitro and in vivo. This way, we aimed to get more insight into the complex interplay between bacteria and differentiation with regard to the potential impact of the microbiota on intestinal inflammation and cancer development.

\section{Materials and Methods}

\section{Cell Culture Experiments}

The colon adenocarcinoma cell line LS174T (American Type Culture Collection, Manassas, USA) was cultivated in Dulbecco's modified Eagle medium (DMEM, Gibco Life Technologies, Eggenstein, Germany) in a humidified atmosphere at $37^{\circ} \mathrm{C}$ and $5 \% \mathrm{CO}_{2} .10 \%$ fetal calf serum (FCS, PAA Laboratories, Pasching, Austria), 1\% non-essential amino acids (Gibco Life Technologies), $1 \%$ penicillin/streptomycin (Gibco Life Technologies) and $1 \%$ sodium pyruvate (Gibco Life Technologies) was added. For experiments, cells were seeded in 12-well culture plates (Becton Dickinson, Franklin Lakes, New Jersey, USA) at a density of $0.65 \times 10^{6}$ per well and grown to about $70 \%$ confluence. Then cells were washed with phosphate-buffered saline (PBS, Gibco Life

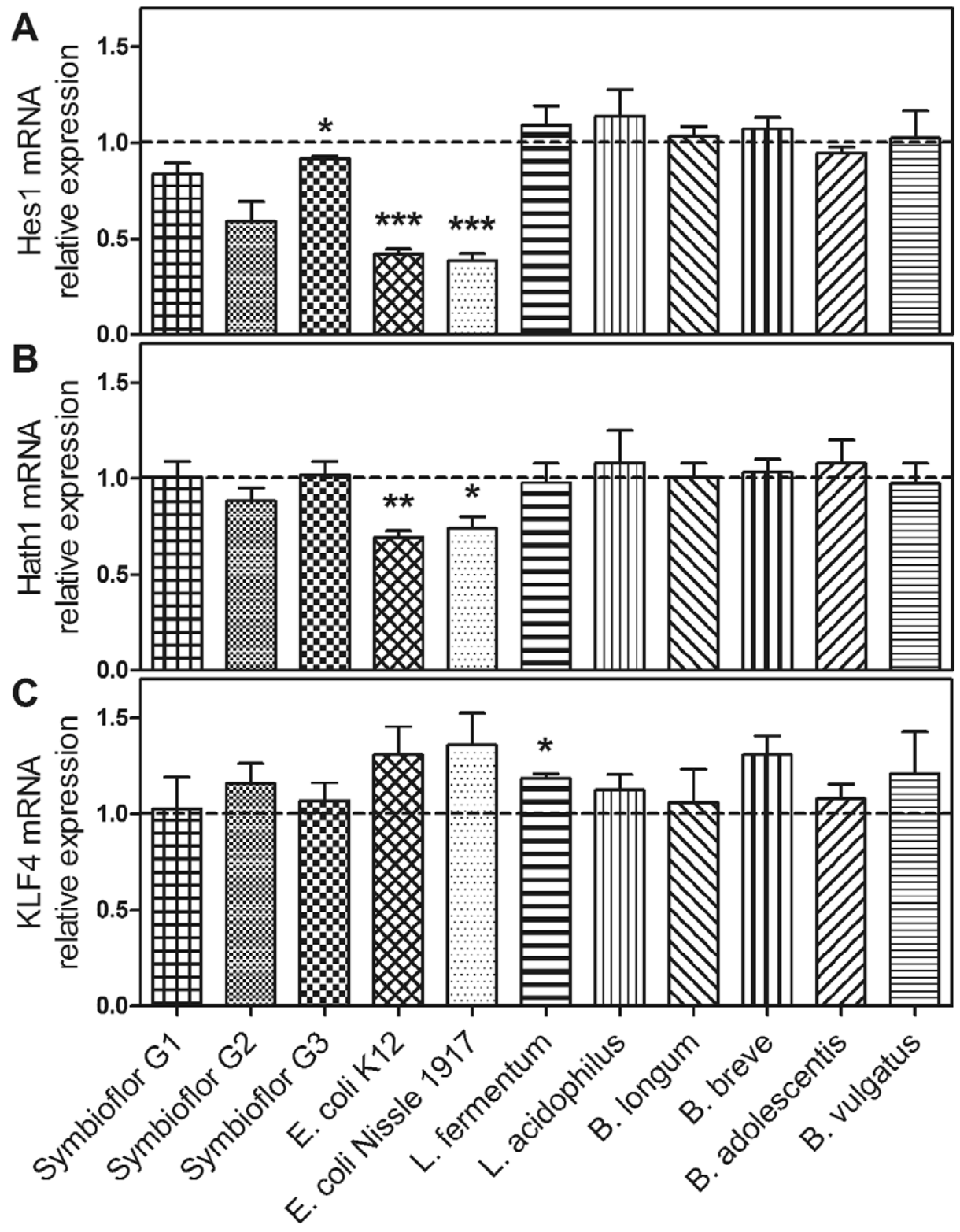

Figure 1. Hes1, Hath1 and KLF4 mRNA expression in LS174T cells after treatment with different heat-inactivated bacteria for 3 hours. Hes 1 expression was impaired by Symbioflor G3, E. coli K-12 and E. coli Nissle 1917 (A). Hath1 transcripts were downregulated by E. coli K-12 and E. coli Nissle 1917 (B). KLF4 mRNA was augmented by L. fermentum (C). Data represent the means \pm SEM normalised to basal expression of untreated controls set at $1(n=4) .^{*}: p<0.05,{ }^{* *}: p<0.01,{ }^{* * *}: p<0.001$. For 12 hours treatment results see Fig. S1.

doi:10.1371/journal.pone.0055620.g001 

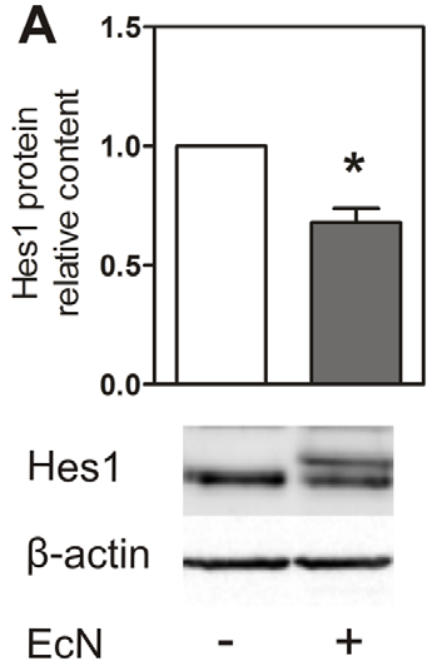
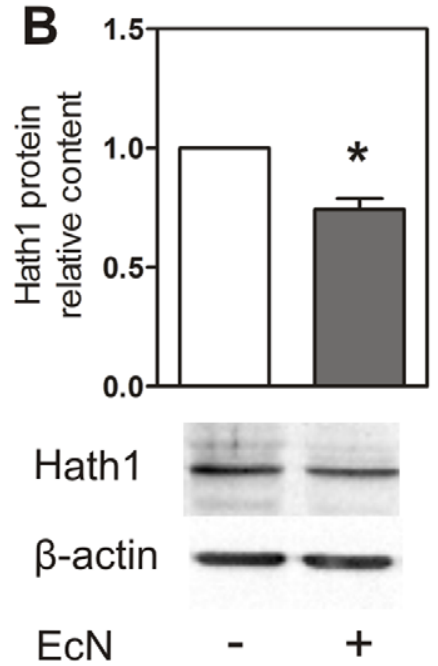
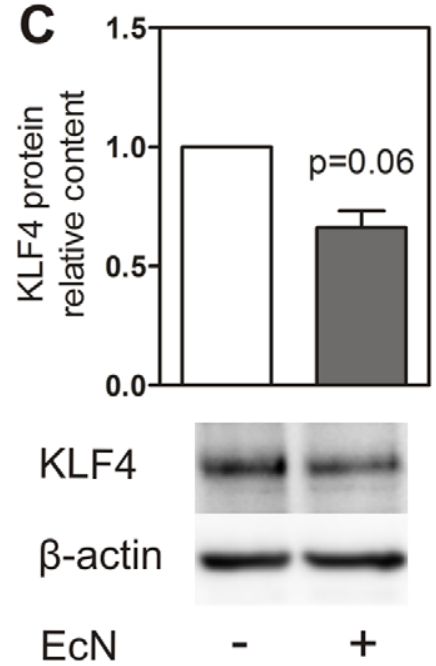

Figure 2. Hes1, Hath 1 and KLF4 protein expression (Western blot) in LS174T cells after treatment with heat-inactivated E. coli Nissle 1917. Hes 1 Western blot analysis showed a double band after incubation (A). The protein content of the lower band (equivalent to the control band) was significantly decreased in comparison to controls after 12 hours of treatment (A). Hath1 protein was significantly decreased after 6 hours treatment with E. coli Nissle 1917 (B). KLF4 was clearly downregulated after 24 hours of treatment (C). Data represent the means \pm SEM normalised to basal expression of untreated controls set at $1(n=3)$. ${ }^{*} p<0.05$. doi:10.1371/journal.pone.0055620.g002

Technologies) and incubated in FCS- and antibiotic-free DMEM for 12 hours.

To investigate the possible role of several bacteria in the regulation of epithelial differentiation, LS174T cells were treated with heat-inactivated E. coli strains Symbioflor G1, G2 and G3, Escherichia coli K-12, E. coli Nissle 1917, Lactobacillus fermentum and acidophilus, Bifidobacterium longum, breve and adolescentis as well as Bacteroides vulgatus for 3 and 12 hours. LS174T cells were also incubated for 3 hours with $E$. coli Nissle 1917 wild type and $E$. coli Nissle 1917 mutant strains EcN $\Delta$ fliA, EcN $\Delta f l i C$, EcN $\Delta f l g E$, $\mathrm{EcN} \Delta f i m, \mathrm{EcN} \Delta f o c$ and $\mathrm{EcN} \Delta \operatorname{csg} B A$, which were kindly provided by $\mathrm{T}$. Oelschlaeger (Institute for Molecular Biology of Infection, University of Würzburg, Germany). The characteristics of the used bacterial strains are summarized in table 1 . All E. coli strains and $B$. vulgatus were grown under aerobic, Lactobacilli and Bifidobacteria under anaerobic conditions as described previously [30]. For experiments, bacteria were heat-inactivated in a water bath at $65^{\circ} \mathrm{C}$ for 1 hour, washed with PBS and adjusted to a density of $3 \times 10^{8}$ cells $/ \mathrm{ml}$ with FCS- and antibiotic-free DMEM.

The possible involvement of Notch signalling was investigated by the treatment of LS174T cells with the $\gamma$-secretase (Notch) inhibitor dibenzazepine (DBZ, Axon Medchem, Groningen, Netherlands) in a concentration of $1 \mu \mathrm{M}$ (in $0.1 \%$ DMSO in DMEM) for 3, 6, 12 and 24 hours in absence or presence of $E$. coli Nissle 1917

After incubation, LS174T cells were rinsed in PBS and mRNA (for PCR measurements) or total protein (for Western blot experiments) was isolated as described below. All cell culture experiments were performed for at least 3 independent times in triplicates.

\section{Mouse Tissue}

Colonic samples (mRNA and tissue from whole mouse colonic mucosa) of mice housed in germfree conditions at the University of Ulm, mice housed in specific pathogen free (SPF) conditions at the University of Cologne and germfree mice that were transferred to the SPF facility in Cologne for cohousing with SPF mice for 4 weeks (conventionalized) (all $\mathrm{C} 57 \mathrm{Bl} / 6$ ), were kindly provided by
M. Pasparakis (Institute for Genetics, Centre for Molecular Medicine University of Cologne).

All animal procedures were conducted in accordance with European, national and institutional guidelines and protocols and were approved at 06.08 .2008 from the ethics committee of Tübingen (Regierungspräsidium AZ 35/9185.81-3), Research-Nr. 929.

\section{RNA Isolation and Reverse Transcription}

Treated LS174T cells were washed with PBS and harvested by scraping. Total RNA from the cell lysates was isolated and DNAse digestion was performed as recommended by the supplier to avoid genomic DNA contamination (RNeasy Mini Kit, Qiagen, Hilden, Germany). Subsequently $1 \mu \mathrm{g}$ of total RNA was reverse transcribed into cDNA with oligo (dT) primers and $15 \mathrm{U} / \mu \mathrm{g}$ AMV Reverse Transcriptase (Promega, Madison, USA) according to standard procedures. RNA preparations were used for PCR analysis.

\section{Quantitative Real-time Reverse Transcriptase PCR}

For mRNA quantification, real-time PCR was performed in a SYBR Green fluorescence temperature cycler (LightCycler ${ }^{\circledR}$, Roche Diagnostics, Mannheim, Germany). Single-stranded cDNA (or gene-specific plasmids as controls) corresponding to $10 \mathrm{ng}$ of RNA served as a template for PCR with specific oligonucleotide primer pairs (table 2) as described previously [31]. All primers were checked for specific binding to the sequence of interest using BLAST. Plasmids for each product were synthesized with the TOPO TA Cloning Kit (Invitrogen, Carlsbad, CA, USA) according to the supplier's protocol. PCR-amplified DNA fragments were confirmed by sequencing. The correctly sequenced plasmids were serially diluted for internal standard curves. The mRNA data were normalized to the mRNA of $B$-actin.

\section{Protein Preparation}

LS174T cells were washed with PBS, harvested by scraping and centrifuged for two times at $1300 \mathrm{rpm}$ for 5 minutes. Whole cell lysates were extracted with lysis buffer containing $20 \mathrm{mM}$ Tris- 


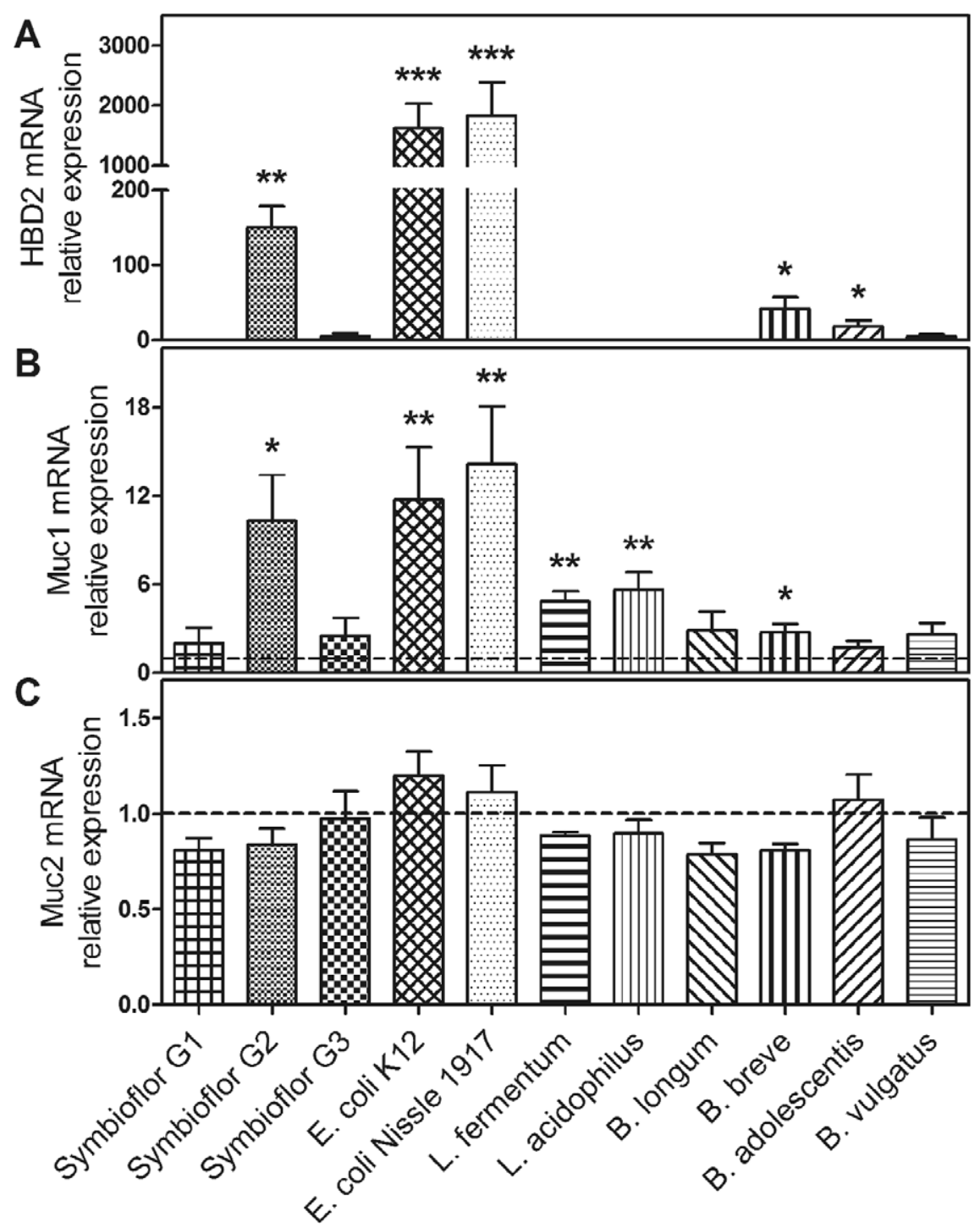

Figure 3. HBD2, Muc1 and Muc2 mRNA expression in LS174T cells after treatment with different heat-inactivated bacteria for 3 hours. HBD2 expression was induced by Symbioflor G2, E. coli K-12, E. coli Nissle 1917, B. breve and adolescentis (A). Muc1 transcripts were upregulated by Symbioflor G2, E. coli K-12, E. coli Nissle 1917, L. fermentum and acidophilus as well as B. breve (B). Muc2 mRNA was unchanged (C). Data represent the means \pm SEM normalised to basal expression of untreated controls set at $1(n=4) .{ }^{*}: p<0.05,{ }^{* *}: p<0.01,{ }^{* * *}: p<0.001$. For 12 hours treatment results see Fig. S2.

doi:10.1371/journal.pone.0055620.g003

HCl pH 7.5, $150 \mathrm{mM} \mathrm{NaCl}, 1 \mathrm{mM}$ EDTA, $1 \%$ Trition X-100, $25 \mathrm{mM}$ Sodiumpyrophosphat, $1 \mathrm{mM}$ Glycerolphosphat, $1 \mathrm{mM} \mathrm{Na}_{3} \mathrm{VO}_{4}, 6 \mathrm{M}$ Urea and $1 \%$ Protease Inhibitor Cocktail (Sigma-Aldrich Chemie GmbH, Steinheim, Germany). Mouse colonic tissue was extracted with lysis buffer (see above) and homogenized by FastPrep instrument. Mouse and cell culture lysates were centrifuged at $13000 \mathrm{rpm}$ at $4^{\circ} \mathrm{C}$ for 20 minutes and the supernatant was collected. Total protein amount was measured with the Bicinchoninic Acid Protein Assay (Smith) as described previously [32]. Isolated proteins were used for Western blot experiments.

\section{Western Blot}

$40 \mu \mathrm{g}$ (LS174T cell lysates) or $20 \mu \mathrm{g}$ (mouse colonic tissue) of total protein was separated on a $10 \%$ Tris-glycin SDS polyacrylamide gel, transferred to $0.45 \mu \mathrm{m}$ pore size nitrocellulose membranes (Schleicher \& Schuell, Keene, NH, USA) and blocked with $5 \%$ skimmed milk powder in TBST $(10 \mathrm{mM}$ Tris $\mathrm{pH} 8.0$, $150 \mathrm{mM} \mathrm{NaCl}, 0.05 \%$ Tween 20) for 1 hour. Then, the membranes were washed with TBST and incubated overnight at $4^{\circ} \mathrm{C}$ with the primary antibodies. Anti-Hath1/Math1 (AB5692, Millipore, Temecula, CA, USA) and anti-Hes1 (sc-25392, Santa Cruz Biotechnology, Heidelberg, Germany) antibodies were diluted 1:200 in 5\% skimmed milk powder in TBST, whereas the dilution of the anti-KLF4 (ab26648, Abcam, Cambridge, USA) antibody was 1:100. After repeatedly washing, the membranes were treated for 1 hour with the secondary HRPconjugated goat anti-rabbit immunoglobulin G antibody (Immuno Research Laboratories, West Grove, PA, USA; dilution 1:5000). Then, protein was detected with the Amersham TM ECL Plus Western Blotting Detection System (GE Healthcare, Chalfont St Giles, UK) and signals were visualized with a chemiluminescence camera charge-coupled device LAS-1000 (Fuji, Tokio, Japan). Densitometric analysis was performed with AIDA 2.1 software 


\section{untreated}
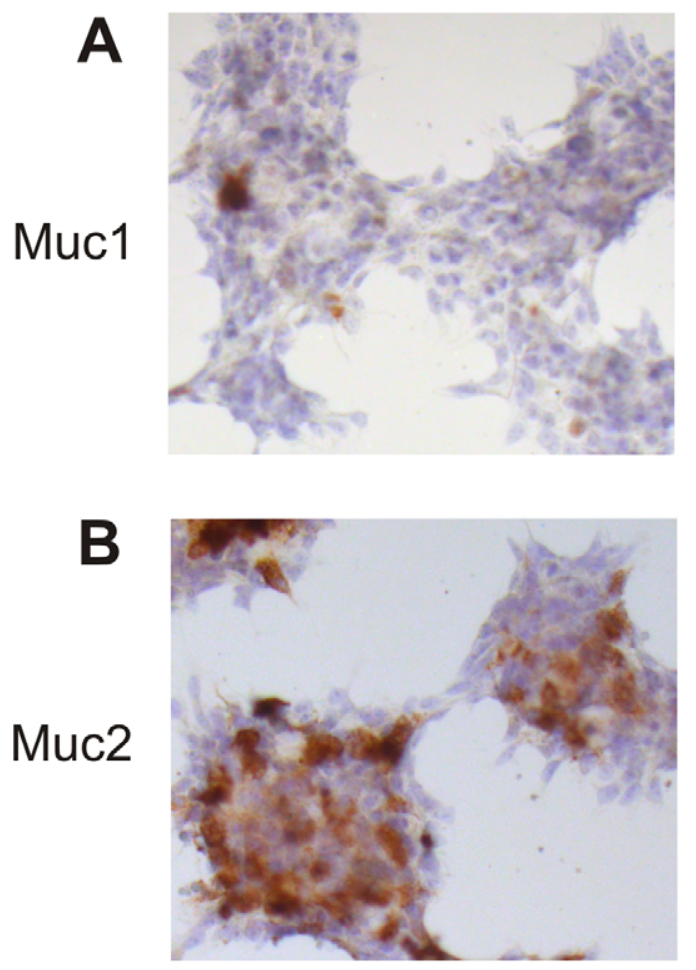

\section{$\mathrm{EcN}$}
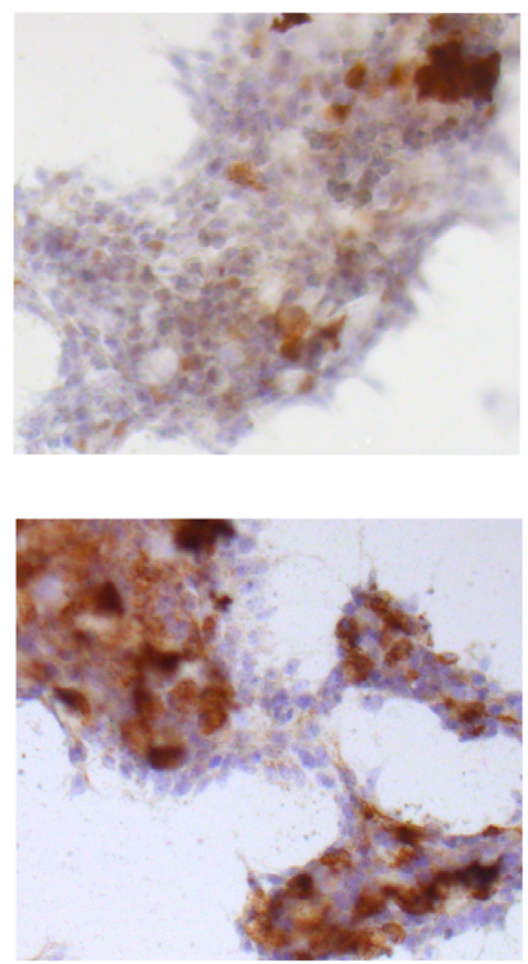

Figure 4. Muc1 and Muc2 protein expression (immunostaining) in LS174T cells after treatment with heat-inactivated $E$. coli Nissle 1917. Staining of Muc1 (A) but not Muc2 (B) was more pronounced following incubation with E. coli Nissle 1917 for 6 hours (representative example of 3 stainings).

doi:10.1371/journal.pone.0055620.g004

(Raytest, Straubenhardt, Germany). B-actin antibody (SigmaAldrich) was used as an internal control.

\section{Immunostaining and Goblet Cell Count}

For Muc1 and Muc2 staining, LS174T cells were seeded in 2well Chamber Slides (Nalge Nunc International Corp., Naperville, IL, USA) at a density of $0.65 \times 10^{6}$ per well. Cells were incubated with $E$. coli Nissle 1917 for 6 hours, washed with PBS and fixed with $100 \%$ ethanol for 10 minutes at $-20^{\circ} \mathrm{C}$. Then, ethanol was removed and the slides were rinsed for two times with TBST. Immunostaining and visualisation was performed as previously described [33]. Anti-Mucl antibody (VU4H5, Santa Cruz Biotechnology, Heidelberg, Germany) was diluted 1:20 and Anti-Muc2 (NCL-Muc2, Leica Biosystems Newcastle Ltd, Balliol Business Park West, United Kingdom) antibody 1:200 in DAKO REAL Antibody dilution buffer (Dako, Glostrup, Denmark). Cells were also counterstained with hematoxylin.

The number of goblet cells was determined in sections from mouse colonic tissue (germfree: $n=6$, SPF housed: $n=4$, conventionalized: $n=4$ ) following a standard Alcian Blue staining by blindly counting the Alcian Blue positive vacuoles in a total of 10 crypts per mice.

\section{Statistics}

Quantitative real-time PCR and Western blot results were analysed using the Mann-Whitney test. Values of $p<0.05$ were considered to be statistically significant. All statistical analyses were performed and all graphs were generated with the GraphPad
Prism version 5.0 software. Data are presented as means with standard error of the mean (SEM).

\section{Results}

Hes1, Hath1 and KLF4 are Regulated by Bacteria in vitro First, we analysed mRNA expression of the epithelial cell differentiation markers Hes1, Hath1 and KLF4 in LS174T cells following treatment with different heat-inactivated bacteria. Hes 1 transcripts (Fig. 1A and Fig. S1A) were diminished following incubation with $E$. coli K-12 (3 hours: 0.42-fold, p $<0.001$; 12 hours: 0.64-fold, $\mathrm{p}<0.001$ ) and E. coli Nissle 1917 (3 hours: 0.38fold, $\mathrm{p}=0.001 ; 12$ hours: 0.67 -fold, $\mathrm{p}<0.001)$. Moreover, 3 hours treatment with Symbioflor G3 (0.92-fold, p =0.023), as well as 12 hours treatment with Symbioflor G2 $(0.75$-fold, $\mathrm{p}=0.043)$ and $L$. acidophilus (0.79-fold, $\mathrm{p}=0.030)$ also led to a downregulation of Hesl mRNA. Hes1 Western blot analysis (Fig. 2A) showed an appearance of a higher molecular weight band after treatment with E. coli Nissle 1917. However, densitometric analysis of the lower molecular weight band that is also present in control cells revealed a significant reduction in Hesl protein levels after 12 hours of E. coli Nissle 1917 stimulation (0.71-fold, $\mathrm{p}=0.047)$.

Hath1 mRNA levels (Fig. 1B and Fig. S1B) were also significantly downregulated by treatment with $E$. coli $\mathrm{K}-12$ (3 hours: 0.69 -fold, $\mathrm{p}=0.002 ; 12$ hours: 0.85 -fold, $\mathrm{p}=0.008$ ) and $E$. coli Nissle 1917 (3 hours: 0.74-fold, $\mathrm{p}=0.025$; 12 hours: 0.80-fold, $\mathrm{p}=0.001)$. This E. coli Nissle 1917 effect on Hathl mRNA expression was confirmed by Western blot analysis showing Hath 1 protein levels to be significantly decreased after 6 hours of bacterial exposure (0.71-fold, $\mathrm{p}=0.038$, Fig. 2B). 


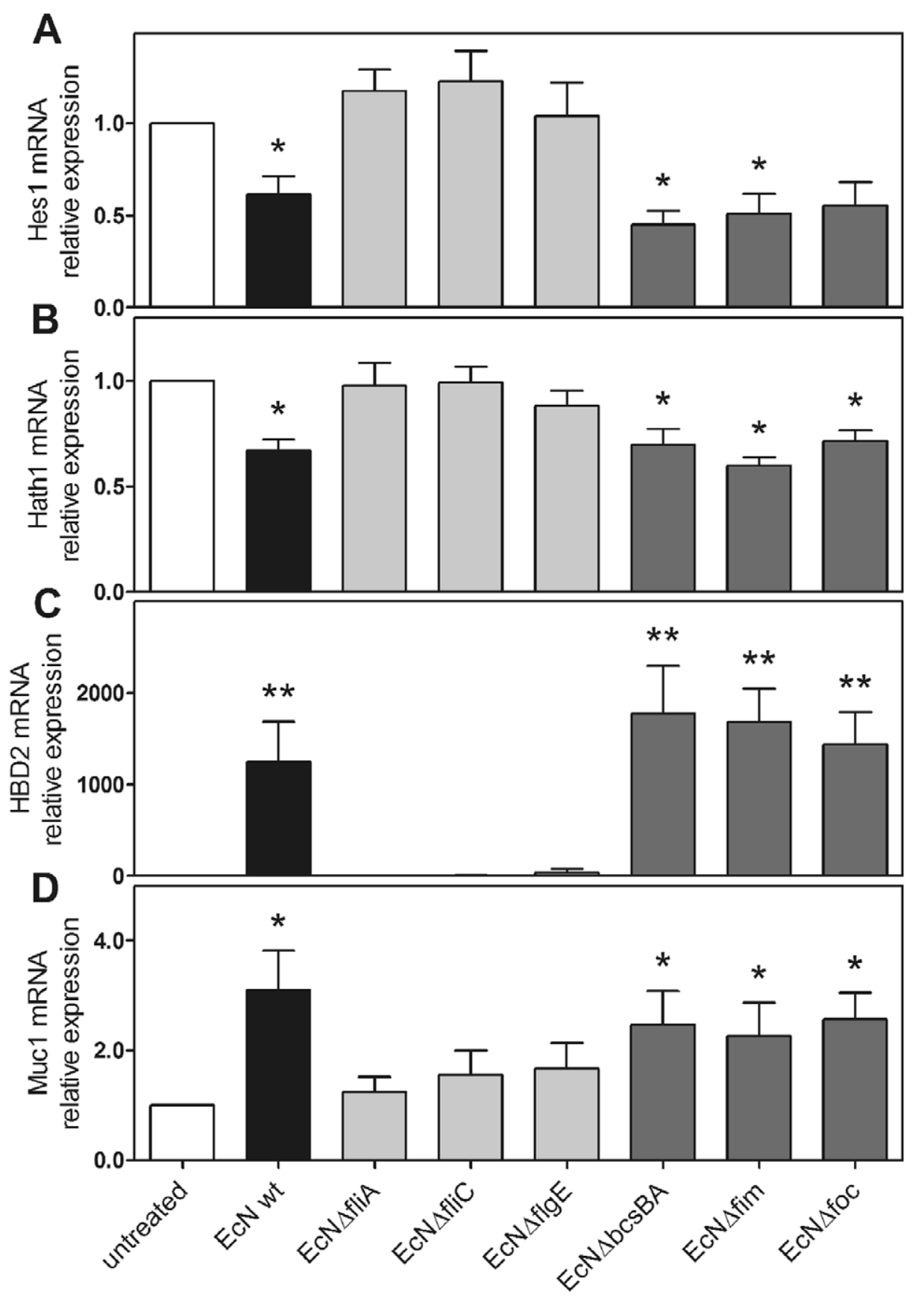

Figure 5. Hes1, Hath1, HBD2 and Muc1 mRNA expression in LS174T cells incubated with heat inactivated $E$. coli Nissle 1917 wild type and mutant strains (see Tab. 1) for 3 hours. Treatment with EcN wt, EcN $\Delta \operatorname{csg} B A$ (curli-negative), EcN $\Delta$ fim (Type 1 pili) and EcN $\Delta$ foc (F1C pili) led to a significant downregulation of Hes1 (A) and Hath1 (B) transcripts, whereas HBD2 (C) and Muc1 (D) mRNA was upregulated. In contrast, EcN $\Delta$ fliA (sigma factor of flagellin), EcN $\Delta$ flic (flagellin), EcN $\Delta f l g E$ (hook) lost the regulation ability. Data represent the means \pm SEM normalised to basal expression of untreated controls set at $1(n=3)$. ${ }^{*}: p<0.05$. doi:10.1371/journal.pone.0055620.g005

KLF4 mRNA transcripts (Fig. $1 \mathrm{C}$ and Fig. S1C) were significantly induced after a 3 hour treatment with $L$. fermentum (1.2-fold, $\mathrm{p}=0.011$, Fig. 1G) and significantly reduced after 12 hours of treatment with E. coli $\mathrm{K}-12$ (0.81-fold, p=0.005), E. coli Nissle 1917 (0.83-fold, $\mathrm{p}=0.008), \quad$ L. acidophilus (0.77-fold, $\mathrm{p}=0.008)$ and $B$. vulgatus $(0.77$-fold, $\mathrm{p}=0.003)$. KLF4 protein levels were also slightly downregulated after 24 hours incubation with E. coli Nissle 1917 (0.69-fold, p = 0.06, Fig. 2C).
HBD2 and Muc1 but not Muc2 are Regulated by Bacteria in vitro

Since downregulation of both Hes 1 and Hathl expression levels could lead to differentiation to either the absorptive or the secretory cell lineage, we further investigated the effect of bacteria on epithelial differentiation by analysing the expression of HBD2, Mucl and Muc2 in LS174T cells after treatment with different bacteria strains. 
A

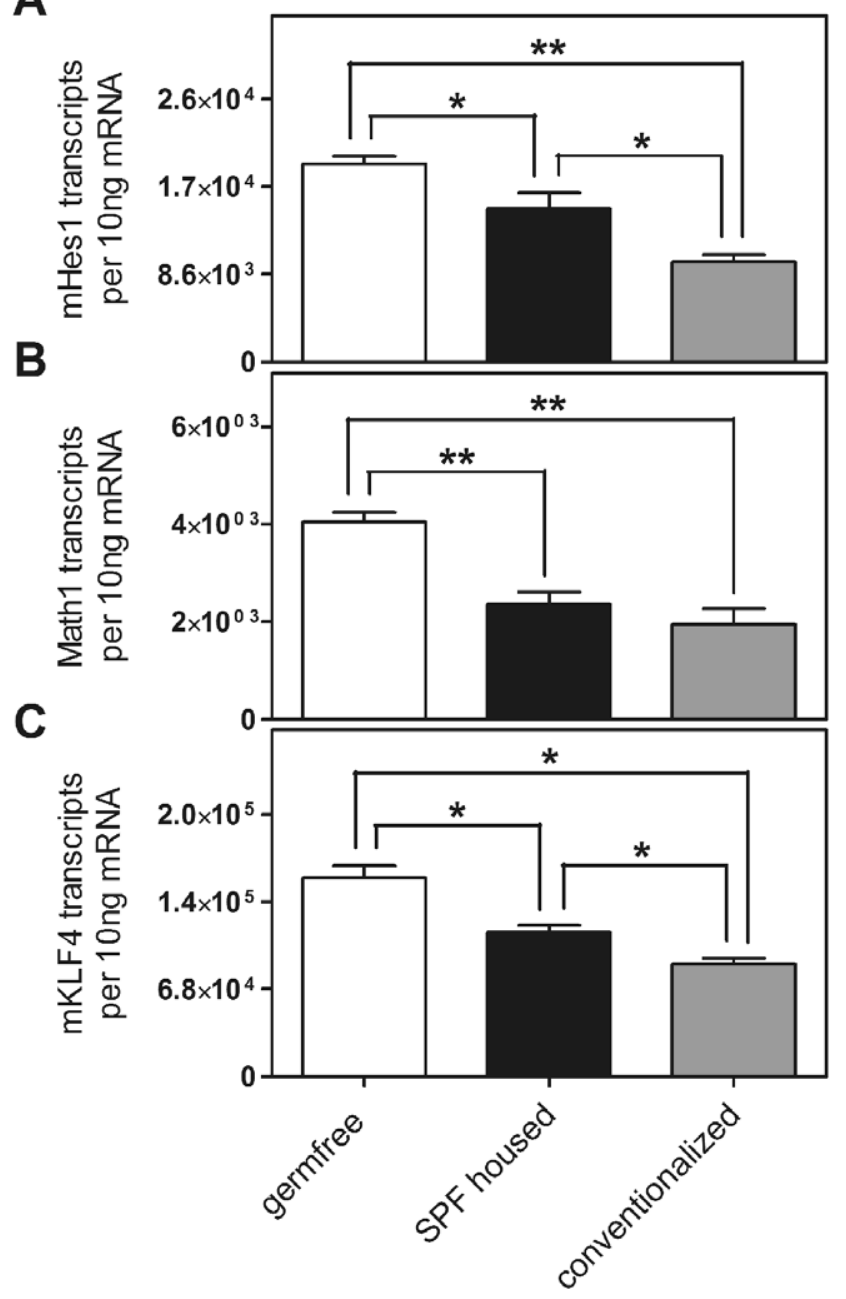

Figure 6. Mouse (m) Hes1, Math1 and mKLF4 mRNA expression in colon of germ free $(n=7)$, SPF (specific pathogen free, $n=4$ ) and conventionalized mice $(\mathbf{n}=\mathbf{4})$. The presence of intestinal microbiota is associated with downregulation of mHes1 (A), Math1 (B) and mKLF4 (C) mRNA in SPF mice and even more in conventionalized mice. Data represent the means \pm SEM normalised to basal expression of untreated controls set at $1 .^{*}: p<0.05,{ }^{* *}: p<0.01$.

doi:10.1371/journal.pone.0055620.g006

HBD2 mRNA (Fig. 3A and Fig. S2A) was induced by Symbioflor G2 (3 hours: 150-fold, $\mathrm{p}=0.002$; 12 hours: 185-fold, $\mathrm{p}<0.001$ ), E. coli K-12 (3 hours: 1630-fold, p<0.001; 12 hours: 1310-fold, p<0.001), E. coli Nissle 1917 (3 hours: 1833-fold, $\mathrm{p}<0.001 ; 12$ hours: 1578-fold, $\mathrm{p}<0.001$ ) and B. breve (3 hours: 42fold, $\mathrm{p}=0.018 ; 12$ hours: 61 -fold, $\mathrm{p}=0.005)$ for both time-points, whereas $B$. adolescentis (18-fold, $\mathrm{p}=0.032$ ) led to a significant increase of HBD2 transcripts only after 3 hours of treatment.

Mucl mRNA transcripts (Fig. 3B and Fig. S2B) were significantly augmented following a 3 hour stimulation with Symbioflor G2 (10-fold, p=0.026), E. coli K-12 (12-fold, $\mathrm{p}=0.002)$, E. coli Nissle 1917 (14-fold, p=0.002), L. fermentum (4.9-fold, $\mathrm{p}=0.002$ ) and acidophilus (5.6-fold, $\mathrm{p}=0.010$ ), as well as B. breve (2.7-fold, $\mathrm{p}=0.049)$. After 12 hours of treatment the Mucl induction was still significant for Symbioflor G2 (2.9-fold, $\mathrm{p}=0.027)$, E. coli K-12 (2.7-fold, $\mathrm{p}=0.018)$ and E. coli Nissle 1917 (3.3-fold, $p=0.008)$. This increase of Mucl mRNA expression after exposure to E. coli Nissle 1917 was confirmed on the protein level by immunocytochemistry (Fig. 4A).

Muc2 mRNA (Fig. 3C and Fig. S2C) expression was unchanged after exposure to intestinal bacteria. Accordingly, incubation with E. coli Nissle 1917 had no effect on Muc2 protein content (Fig. 4B).

To clarify whether the effects on HBD2 and Mucl expression are caused by bacterial treatment or indirectly by changes in Hes 1 and Hathl expression, we blocked the Notch pathway in LS174T cells using the gamma-secretase inhibitor DBZ up to 24 hours with and without E. coli Nissle. The DBZ treatment led to a strong downregulation of Hesl (3 h: 0.34-fold, $p=0.01 ; 6 \mathrm{~h}$ : 0.11-fold, $\mathrm{p}=0.0003 ; 12 \mathrm{~h}: 0.09$-fold, $\mathrm{p}<0.0001$ and $24 \mathrm{~h}: 0.11$-fold, $\mathrm{p}=0.001)$ followed by a delayed Hathl upregulation ( $3 \mathrm{~h}: 0.93-$ fold, n.s.; 6 h: 1.19-fold, $p=0.0206 ; 12$ h: 2.01-fold, $p=0,0297$ and 24 h: 2.44-fold, $\mathrm{p}=0.0032$ ), without affecting HBD2, Mucl or Muc2 expression. Thus, no significant differences in mRNA expression of these products in untreated and DBZ treated cells as well as no differences between $E$. coli Nissle only and E. coli Nissle+DBZ treated cells were observed (Fig. S3 and S4). Since HBD2 and Mucl are induced by E. coli Nissle 1917 independently of Notch pathway inhibition, we suggest that this induction is triggered by bacteria or their components and not through changes in Hesl or Hathl expression.

\section{E. coli Nissle 1917 Flagellin is Required for Regulating Hes1, Hath1, HBD2 and Muc1 Expression}

Since previous data mechanically linked the inducing effect of $E$. coli Nissle 1917 on HBD2 to its flagellin [34], we analyzed whether flagellin is essential to regulate expression of Hesl, Hathl and Muc1. LS174T cells were incubated for 3 hours with E. coli Nissle 1917 wild type strain as well as various E. coli Nissle 1917 deletion mutants as listed in table 1 .

Consistent with our previous observations, KLF4 (Fig. S5A) and Muc2 (Fig. S5B) mRNA levels were unchanged following a 3 hour treatment with $E$. coli Nissle 1917 wild type and mutant strains. In contrast, Hes1 (0.61-fold, p =0.046, Fig. 5A) and Hath1 (0.67-fold, $\mathrm{p}=0.035$, Fig. 5B) mRNA levels were significantly downregulated after 3 hours of treatment with wild type E. coli Nissle 1917 as compared to untreated controls, whereas HBD2 (1246-fold, $p=0.005$, Fig. 5C) and Mucl (3.1-fold, p =0.014, Fig. 5D) mRNA transcripts were upregulated. This change in Hesl and Hathl expression pattern was similar after incubation with the $E$. coli Nissle 1917 mutant strains EcN $\Delta \operatorname{csg} B A$ (Hesl:0.45-fold, $\mathrm{p}=0.015$, Hath1:0.70-fold, $\quad \mathrm{p}=0.044, \quad$ HBD2:1775-fold, $\quad \mathrm{p}=0.002$, Muc1:2.5-fold, $\mathrm{p}=0.034$ ), EcN $\Delta$ fim (Hes 1:0.51-fold, $\mathrm{p}=0.038$, Hath1:0.60-fold, $\quad \mathrm{p}=0.016, \quad$ HBD2:1684-fold, $\mathrm{p}=0.001$, Mucl:2.3-fold, $\mathrm{p}=0.078$ ) and $\mathrm{EcN} \Delta$ foc (Hes1:0.56-fold, $\mathrm{p}=0.067, \quad$ Hath1:0.72-fold, $\mathrm{p}=0.018, \quad$ HBD2:1441-fold, $\mathrm{p}=0.002$ Mucl:2.6-fold, $\mathrm{p}=0.016$ ). In contrast, incubation with the flagellin mutants EcN $\Delta f l i A, \mathrm{EcN} \Delta f l i C$ and $\mathrm{EcN} \Delta f l g E$ left Hesl, Hath1, HBD2 and Mucl mRNA transcripts unchanged as compared to the untreated controls (Fig. 5A-D). These results clearly demonstrate that the flagellin of E. coli Nissle 1917 is essential for regulating Hes1, Hath1, HBD2 and Mucl mRNA expression.

\section{Microbiota also Regulate Hes1, Math1 and KLF4 in vivo}

As our in vitro observations suggested an effect of bacteria on intestinal epithelial cell differentiation, we next evaluated the in vivo relevance of our findings by using germfree animals to assess the role of the intestinal microflora in the regulation of epithelial cell differentiation in mice. Therefore, mRNA expression of mHes1, Math1 (the mouse homolog of Hath1), mKLF4, mMucl and mMuc2 was analyzed in the colon of germfree mice as 


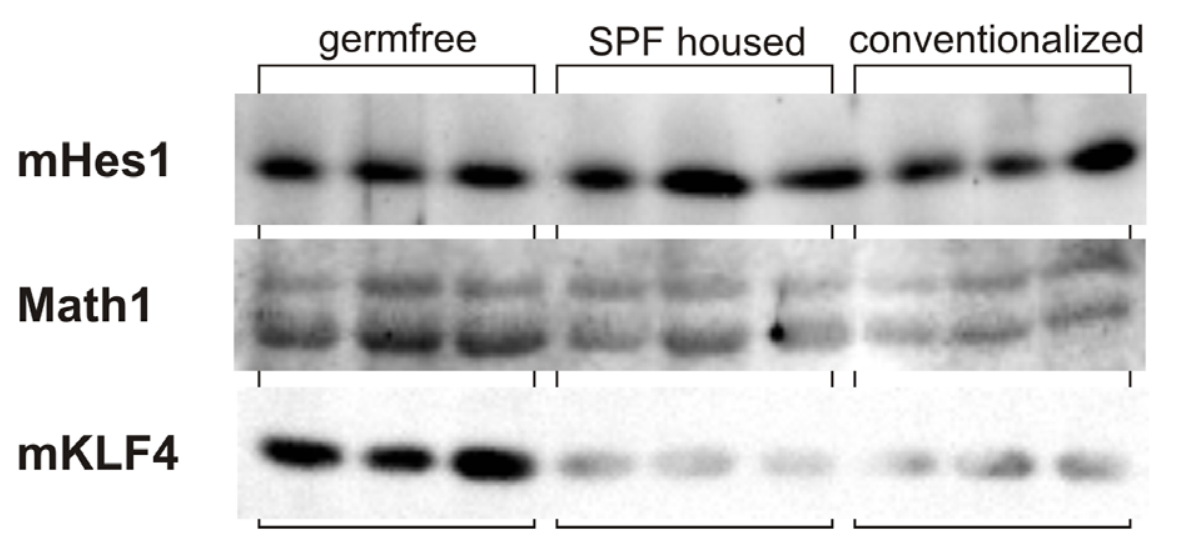

Figure 7. Mouse (m) Hes1, Math1 and mKLF4 protein expression in colon of germ free, SPF (specific pathogen free) and conventionalized mice. The presence of intestinal microbiota is associated with a downregulation of Math1 and mKLF4 but not mHes1 protein in SPF and conventionalized mice.

doi:10.1371/journal.pone.0055620.g007

compared to mice reared with specific pathogen free (SPF) intestinal microflora (m...mouse). In the colon of SPF mice, mRNA expression of mHes1 (0.77-fold, $\mathrm{p}=0.04)$, Math $1(0.58-$ fold, $p=0.006)$ and mKLF4 (0.73-fold, $p=0.011)$ was lower in comparison to germfree mice (Fig. 6A-C). These results are consistent with our in vitro observations suggesting an inhibitory
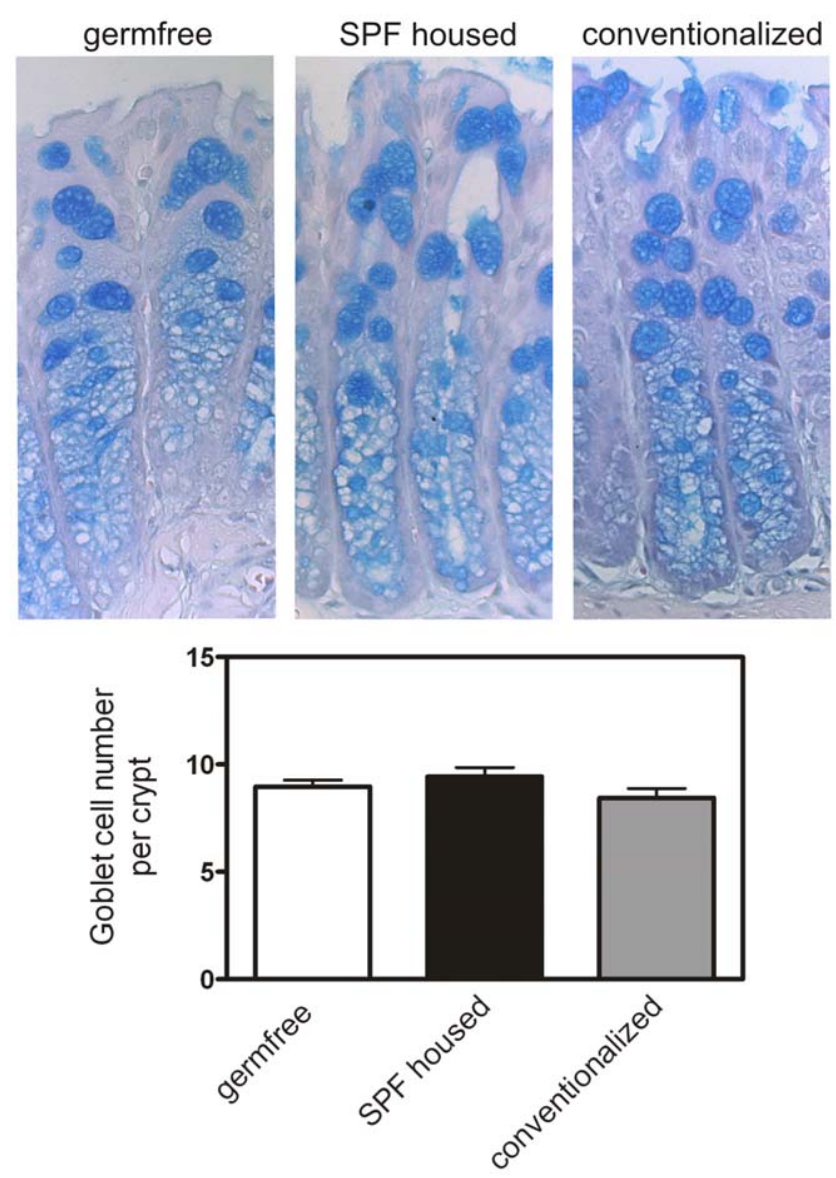

Figure 8. Goblet cell number in colon of germ free, SPF (specific pathogen free) and conventionalized mice. The number of goblet cells is unchanged between the three subgroups. doi:10.1371/journal.pone.0055620.g008 effect of bacteria on expression of these differentiation genes. In order to further evaluate this, we also analyzed colons from germfree mice that regained their microbiota by cohousing with SPF mice for 4 weeks. These conventionalised mice showed even more decreased mRNA levels for mHesl (0.51-fold $\mathrm{p}=0.006)$, Math 1 (0.48-fold, $\mathrm{p}=0.006)$ and $\mathrm{mKLF} 4(0.57$-fold $\mathrm{p}=0.011)$ as compared to the germfree mice (Fig. $6 \mathrm{~A}-\mathrm{C}$ ), again confirming the inhibitory effect of the microbiota on expression of these differentiation factors. Surprisingly however, this microbiota effect was not reflected in the expression levels of mMucl (Fig. S6A) and mMuc2 (Fig. S6B) since they were not significantly altered in germfree versus colonized mice.

In accordance with the mRNA data we also found a diminished colonic Mathl and mKLF4 protein expression by Western blot analysis in SPF housed and conventionalized mice as compared to the germfree animals (Fig. 7). In contrast, mHes 1 protein seems to be unchanged in these three groups (Fig. 7). However, the diminished expression of the goblet cell differentiation markers Math1 and mKLF4 does not lead to a reduced number of goblet cells as shown in Fig. 8.

\section{Discussion}

The current study focused on the regulatory effects of intestinal bacteria on the expression of the intestinal epithelial differentiation factors Hes1, Hathl and KLF4. Moreover the bacterial effects on mucins Mucl and Muc2, as well as the defensin HBD2 were investigated as well.

We found a bacterial regulation of the transcription factors Hes1, Hathl and KLF4 in the colon adenocarcinoma cell line LS174T, especially by $E$. coli K-12 and E. coli Nissle 1917 . These changes in mRNA expression were confirmed for Hesl and Hathl (and also in trend for KLF4) on the protein level by Western blot experiments following stimulation with E. coli Nissle 1917. Notably, in case of Hesl, a higher molecular weight band appeared following treatment with $E$. coli Nissle 1917. This double band did not occur in the mouse colon where only a single band was observed, therefore we conclude that the double band is an in vitro phenomenon of cell culture and has likely no physiological relevance in vivo. However, to our knowledge, this is the first study that shows bacteria to regulate these three epithelial differentiation factors in colonic epithelial cells in vitro. Prior observations demonstrated Hesl to be induced by Porphyromonas gingivalis lipopolysaccharides in the mouse osteoblastic cell line MC3T3E- 
1 and in primary mouse bone marrow stromal cells [35]. Moreover Mycobacterium bovis led to increased Hesl transcripts in peritoneal mice macrophages [36] whereas Salmonella typhimurium causes a decrease of Hesl expression in PS cells [37]. In case of Hath 1 , there are no data available concerning the interaction with bacteria at all, whereas KLF4 was shown to be induced in macrophages again by $P$. gingivalis lipopolysaccharides [38]. In the present study Mucl expression of LS174T cells was also significantly induced by several bacteria, such as E. coli Nissle 1917 and E. coli K-12, whereas Muc2 expression was unchanged following incubation with all bacteria strains tested. Accordingly, immunostaining on LS174T cells showed a clear induction of Mucl protein following stimulation with E. coli Nissle 1917 as compared to untreated cells, whereas Muc2 protein was unaffected. Several, in part conflicting studies, focused on the impact of bacteria on the expression profiles of the mucins Muc1 and Muc2 in intestinal epithelial cells. For instance, HT29 cells treated with E. coli Nissle 1917 did not alter the mRNA and protein expression of these two mucins. In contrast, the probiotic cocktail VSL\#3 induced Muc2 secretion in HT29 cells [39] but not in LS174T cells [40]. Moreover, L. acidophilus enhanced Muc2 transcripts in HT29 cells [41], whereas another group could not confirm these data [42]. A recent study showed a strong up-regulation of Muc2 in LS174T cells after treatment with flagellin from Salmonella typhimurium [43]. Differences between these prior observations and our data could be explained by the use of different cell lines (e.g. HT-29 vs. LS174T cells) and possibly also by different bacterial preparations (e.g. living vs. heat-inactivated bacteria).

In addition, we found HBD2 transcripts to be upregulated by $E$. coli Nissle 1917, E. coli K-12, and other bacteria. This is in principle consistent with prior data where HBD2 mRNA was demonstrated to be induced in Caco-2 cells following a treatment with $E$. coli Nissle 1917, uropathogenic $E$. coli, as well as $L$. fermentum, L. acidophilus and VSL\#3, but not with E. coli K-12 [30]. Moreover, in LS174T cells the expression of HBD2 was shown to be elevated once treated with E. coli D21, Micrococcus luteus and Salmonella typhimurium [44]. Notably, the effect of L. fermentum on HBD2 expression was clearly higher in Caco-2 than in LS174T cells. This also implies that HBD2 regulation varies in different cell lines.

Overall, cell culture experiments showed a stronger downregulation of the columnar cell differentiation marker Hesl, as compared to the secretory cell differentiation marker Hathl. Therefore, it could be speculated that specific bacteria such as $E$. coli Nissle 1917 and $E$. coli K-12 may influence the differentiation of specific cell lineages with a shift towards the goblet cell lineage. Nevertheless, the interplay of underlying mechanisms and the exact consequences of the effects on the differentiation markers need further study.

Previously, the induction of HBD2 by E. coli Nissle 1917 was demonstrated to be dependent on flagellin [34]. Since Hes1, Hathl and Mucl were also regulated by E. coli Nissle 1917, we analyzed the role of flagellin with respect to these three factors. In contrast to E. coli Nissle 1917 wild type, Hesl and Hath 1 mRNA was not downregulated by the flagellin mutant strains $\mathrm{EcN} \Delta f l i A$, $\mathrm{EcN} \Delta f i C$ and EcN $\Delta f l g E$. Accordingly, Mucl expression was enhanced in E. coli Nissle 1917 wild type, but not in EcN $\Delta$ fliA, $\mathrm{EcN} \Delta f l i C$ and $\mathrm{EcN} \Delta f l g E$. This implies that Hes 1, Hath 1 and Mucl are regulated by $E$. coli Nissle 1917 flagellin, similar to HBD2.

To elucidate the effect of the intestinal microflora in vivo, we analysed the expression of mHes1, Mathl and mKLF4 in the colon of germ free mice compared to SPF and conventionalized mice. Similar to the cell culture data, we observed a significantly lower Mathl and mKLF4 mRNA and protein expression in colonized mice compared to germ free mice, whereas mHesl expression was reduced on mRNA but not on protein level. This difference in mHes 1 expression could be a result of posttranscriptional regulation mechanisms which need further investigations.

Several arguments underline that intestinal bacteria play a crucial role in IBD pathogenesis: Inflammation in IBD is located in areas with a high density of bacteria (mostly colon and/or terminal ileum) [45]; germ free mice do not develop colitis [46]; exposure of fecal stream to the terminal ileum worsen inflammation [47]; antimicrobial peptides are insufficiently expressed in $\mathrm{CD}$, and mutations of human receptors recognizing luminal bacteria, such as NOD2 [48,49] and TLR dysfunction [50,51] are linked to a higher risk of IBD development. Moreover, the intestinal microflora is altered in IBD as compared to healthy controls. Numerous studies described changes in the composition of the microflora between CD, UC and healthy patients [52-54], and mucosa-associated and even intracellular bacteria were found in both types of IBD $[17,18]$. Recent studies showed UC to be associated with goblet cell [21] and ileal CD with Paneth cell differentiation defects [20]. In addition, mice with an epithelialspecific defect leading to reduced Hesl expression were recently shown to spontaneously develop colitis [55]. Considering these observations, our data suggest that in addition to the genetic predisposition, the luminal microbiota may directly affect epithelial differentiation and its defensive role.

There are also reasons to suggest bacteria to be involved in colon cancer pathogenesis: intestinal cancer is mostly found in the colon, the segment with the highest number of bacteria [56], some bacteria can induce malignancies, e.g. H. pylori and gastric neoplasia $[57,58]$, and, moreover, patients with colon cancer have adherent bacteria [27] as well as more circulating antibodies against specific bacteria (e.g. S. gallolyticus) compared to healthy controls [59]. On the other hand, several studies reported that probiotics, such as L. acidophilus NCFM, suppress carcinogenesis [60,61]. In most colorectal cancers Notch signaling was found to be activated [62,63], whereas Hath1 and KLF4 were decreased [64-67]. It may be speculated that the downregulation of the important epithelial cell differentiation factors Hath1 and KLF4 could play a role in this regard.

Taken together, the current study shows that intestinal bacteria regulate the epithelial differentiation factors Hes1, Hathl and KLF4 in vitro and in vivo. This could be involved in IBD and colon cancer pathogenesis although further details remain to be elucidated.

\section{Supporting Information}

Figure S1 Hes1, Hath1 and KLF4 mRNA expression in LS174T cells after treatment with different heat-inactivated bacteria for 12 hours. Hesl expression was diminished by Symbioflor G2, E. coli K-12, E. coli Nissle 1917 and L. acidophilus (A). Hath 1 transcripts were downregulated by E. coli K-12 and $E$. coli Nissle 1917 (B). KLF4 mRNA was impaired by E. coli K-12, E. coli Nissle 1917, L. acidophilus and B. vulgatus $(\mathrm{C})$. Data represent the means \pm SEM normalised to basal expression of untreated controls set at $1(\mathrm{n}=4) . *$ : $<<0.05, * *: \mathrm{p}<0.01, * * *: \mathrm{p}<0.001$.

(TIF)

Figure S2 HBD2, Muc1 and Muc2 mRNA expression in LS174T cells after treatment with different heat-inactivated bacteria for 12 hours. HBD2 expression was induced by Symbioflor G2, E. coli K-12, E. coli Nissle 1917 and B. breve (A). Mucl transcripts were upregulated by Symbioflor G2, E. coli K-12 and E. coli Nissle 1917 (B). Muc2 mRNA was unchanged (C). Data represent the means \pm SEM normalised to basal expression of 
untreated controls set at $1(\mathrm{n}=4) . *$ : $<<0.05, * *: \mathrm{p}<0.01$, ***: $\mathrm{p}<0.001$.

(TIF)

Figure S3 Hes1, Hath1 and KLF4 mRNA expression in LS174T cells following treatment with $E$. coli Nissle 1917, DBZ and $E$. coli Nissle 1917+DBZ for 3, 6, 12 and 24 hours. DBZ led to a strong downregulation of Hesl after 3 to 24 hours treatment (A), a significant upregulation of Hath 1 after 6 to 24 hours treatment (B) and an increase of KLF4 mRNA expression following 24 hours treatment $(\mathrm{C})$. Data represent the means \pm SEM normalised to basal expression of untreated controls set at $1(n=4) . *: p<0.05, * *: p<0.01, * * *: p<0.001$. (TIF)

Figure S4 HBD2, Muc1 and Muc2 mRNA expression in LS174T cells following treatment with $E$. coli Nissle 1917, DBZ and $E$. coli Nissle 1917+ DBZ for 3, 6, 12 and 24 hours. E. coli Nissle 1917 upregulated HBD2 and Mucl transcripts independent of DBZ treatment $(\mathrm{A}+\mathrm{B})$. Muc2 mRNA expression was unchanged by DBZ and/or E. coli Nissle 1917 (C). Data represent the means \pm SEM normalised to basal expression of untreated controls set at $1(\mathrm{n}=4))^{*}: \mathrm{p}<0.05, * *$ : $<<0.01$, ***: $\mathrm{p}<0.001$.

(TIF)

Figure S5 KLF4 and Muc2 mRNA expression in LS174T cells incubated with heat inactivated $E$. coli Nissle 1917 wild type and mutant strains (see Tab. 1) for 3 hours.

\section{References}

1. Gill SR, Pop M, Deboy RT, Eckburg PB, Turnbaugh PJ, et al. (2006) Metagenomic analysis of the human distal gut microbiome. Science 312: 13551359 .

2. Ley RE, Peterson DA, Gordon JI (2006) Ecological and evolutionary forces shaping microbial diversity in the human intestine. Cell 124: 837-848.

3. Sears CL (2005) A dynamic partnership: celebrating our gut flora. Anaerobe 11: $247-251$.

4. Shirazi T, Longman RJ, Corfield AP, Probert CS (2000) Mucins and inflammatory bowel disease. Postgrad Med J 76: 473-478.

5. Ayabe T, Satchell DP, Wilson CL, Parks WC, Selsted ME, et al. (2000) Secretion of microbicidal alpha-defensins by intestinal Paneth cells in response to bacteria. Nat Immunol 1: 113-118.

6. Wehkamp J, Salzman NH, Porter E, Nuding S, Weichenthal M, et al. (2005) Reduced Paneth cell alpha-defensins in ileal Crohn's disease. Proc Natl Acad Sci U S A 102: 18129-18134.

7. Wehkamp J, Schmid M, Stange EF (2007) Defensins and other antimicrobial peptides in inflammatory bowel disease. Curr Opin Gastroenterol 23: 370-378.

8. Zhao C, Wang I, Lehrer RI (1996) Widespread expression of beta-defensin hBD-1 in human secretory glands and epithelial cells. FEBS Lett 396: 319-322.

9. Meyer-Hoffert U, Hornef MW, Henriques-Normark B, Axelsson LG, Midtvedt $\mathrm{T}$, et al. (2008) Secreted enteric antimicrobial activity localises to the mucus surface layer. Gut 57: 764-771.

10. Crosnier C, Stamataki D, Lewis J (2006) Organizing cell renewal in the intestine: stem cells, signals and combinatorial control. Nat Rev Genet 7: 349-359.

11. Yang Q Bermingham NA, Finegold MJ, Zoghbi HY (2001) Requirement of Math1 for secretory cell lineage commitment in the mouse intestine. Science 294: 2155-2158.

12. Jensen J, Pedersen EE, Galante P, Hald J, Heller RS, et al. (2000) Control of endodermal endocrine development by Hes-1. Nat Genet 24: 36-44.

13. Katz JP, Perreault N, Goldstein BG, Lee CS, Labosky PA, et al. (2002) The zincfinger transcription factor Klf4 is required for terminal differentiation of goblet cells in the colon. Development 129: 2619-2628.

14. Gersemann M, Stange EF, Wehkamp J (2003) From intestinal stem cells to inflammatory bowel diseases. World J Gastroenterol 17: 3198-3203.

15. Gersemann M, Wehkamp J, Fellermann K, Stange EF (2008) Crohn's diseasedefect in innate defence. World J Gastroenterol 14: 5499-5503.

16. Sartor RB (2008) Microbial influences in inflammatory bowel diseases. Gastroenterology 134: 577-594.

17. Darfeuille-Michaud A, Boudeau J, Bulois P, Neut C, Glasser AL, et al. (2004) High prevalence of adherent-invasive Escherichia coli associated with ileal mucosa in Crohn's disease. Gastroenterology 127: 412-421.

18. Swidsinski A, Loening-Baucke V, Theissig F, Engelhardt H, Bengmark S, et al. (2006) Comparative study of the intestinal mucous barrier in normal and inflamed colon. Gut 56(3): 343-350.
KLF4 (A) and Muc2 (B) mRNA expression was unchanged in $E$. coli Nissle wild type $(\mathrm{EcN} w \mathrm{w})$ and mutant strains (EcN $\Delta$ fliA, EcN $\Delta f l i C, \operatorname{EcN} \Delta f l g E, \operatorname{EcN} \Delta \operatorname{csg} B A, \operatorname{EcN} \Delta f i m, \operatorname{EcN} \Delta f o c)$. Data represent the means \pm SEM normalised to basal expression of untreated controls set at $1(\mathrm{n}=4)$.

(TIF)

Figure S6 Mouse (m) Muc1 and Muc2 mRNA expression in colon of germ free $(n=7)$, SPF (specific pathogen free, $\mathbf{n}=4)$ and conventionalized mice $(\mathbf{n}=4)$. No significant changes on mMucl (A) and mMuc2 (B) expression were found between the subgroups.

(TIF)

\section{Acknowledgments}

This study was supported by the Robert Bosch Foundation (Stuttgart, Germany), the Sonderforschungsbereich (SFB) 685 (University of Tuebingen) and Emmy Noether program (J.W.) of the Deutsche Forschungsgemeinschaft (DFG). The authors are grateful to Dr. Katerina Vlantis, Jutta Bader and Marion Schiffmann for excellent technical support.

\section{Author Contributions}

Analyzed the data: SB JW EFS MG. Wrote the paper: SB EFS MG. Conceived and designed the experiments: SB EFS MG. Contributed reagents/materials/analysis tools: TAO AW MP. Performed the experiments: SB MG.

19. Wehkamp J, Wang G, Kubler I, Nuding S, Gregorieff A, et al. (2007) The Paneth cell alpha-defensin deficiency of ileal Crohn's disease is linked to Wnt/ Tcf-4. J Immunol 179: 3109-3118.

20. Koslowski MJ, Kubler I, Chamaillard M, Schaeffeler E, Reinisch W, et al. (2009) Genetic variants of Wnt transcription factor TCF-4 (TCF7L2) putative promoter region are associated with small intestinal Crohn's disease. PLoS ONE 4: e4496.

21. Gersemann M, Becker S, Kubler I, Koslowski M, Wang G, et al. (2009) Differences in goblet cell differentiation between Crohn's disease and ulcerative colitis. Differentiation 77: 84-94.

22. Zheng X, Tsuchiya K, Okamoto R, Iwasaki M, Kano Y, et al. (2011) Suppression of hath1 gene expression directly regulated by hesl via notch signaling is associated with goblet cell depletion in ulcerative colitis. Inflamm Bowel Dis 17: 2251-2260.

23. McCormick DA, Horton LW, Mee AS (1990) Mucin depletion in inflammatory bowel disease. J Clin Pathol 43: 143-146.

24. Pullan RD, Thomas GA, Rhodes M, Newcombe RG, Williams GT, et al. (1994) Thickness of adherent mucus gel on colonic mucosa in humans and its relevance to colitis. Gut 35: 353-359.

25. Biarc J, Nguyen IS, Pini A, Gosse F, Richert S, et al. (2004) Carcinogenic properties of proteins with pro-inflammatory activity from Streptococcus infantarius (formerly S.bovis). Carcinogenesis 25: 1477-1484.

26. Newman JV, Kosaka T, Sheppard BJ, Fox JG, Schauer DB (2001) Bacterial infection promotes colon tumorigenesis in $\mathrm{Apc}(\mathrm{Min} /+)$ mice. J Infect Dis 184: $227-230$.

27. Swidsinski A, Khilkin M, Kerjaschki D, Schreiber S, Ortner M, et al. (1998) Association between intraepithelial Escherichia coli and colorectal cancer. Gastroenterology 115: 281-286.

28. Abdulamir AS, Hafidh RR, Mahdi LK, Al-jeboori T, Abubaker F (2009) Investigation into the controversial association of Streptococcus gallolyticus with colorectal cancer and adenoma. BMC Cancer 9: 403.

29. Gupta A, Madani R, Mukhtar H (2010) Streptococcus bovis endocarditis, a silent sign for colonic tumour. Colorectal Dis 12: 164-171.

30. Wehkamp J, Harder J, Wehkamp K, Wehkamp-von Meissner B, Schlee M, et al. (2004) NF-kappaB- and AP-1-mediated induction of human beta defensin-2 in intestinal epithelial cells by Escherichia coli Nissle 1917: a novel effect of a probiotic bacterium. Infect Immun 72: 5750-5758.

31. Wehkamp J, Harder J, Weichenthal M, Mueller O, Herrlinger KR, et al. (2003) Inducible and constitutive beta-defensins are differentially expressed in Crohn's disease and ulcerative colitis. Inflamm Bowel Dis 9: 215-223.

32. Stoscheck CM (1990) Quantitation of protein. Methods Enzymol 182: 50-68.

33. Schmid M, Fellermann K, Fritz P, Wiedow O, Stange EF, et al. (2007) Attenuated induction of epithelial and leukocyte serine antiproteases elafin and secretory leukocyte protease inhibitor in Crohn's disease. J Leukoc Biol doi: 10.1189/jlb.0906581 
34. Schlee M, Wehkamp J, Altenhoefer A, Oelschlaeger TA, Stange EF, et al. (2007) The Induction of Human Beta-Defensin-2 by the Probiotic Escherichia coli Nissle 1917 is Mediated through Flagellin. Infect Immun 75(5): 2399-407.

35. Xing Q Ye Q, Fan M, Zhou Y, Xu Q et al. (2010) Porphyromonas gingivalis lipopolysaccharide inhibits the osteoblastic differentiation of preosteoblasts by activating Notch1 signaling. J Cell Physiol 225: 106-114.

36. Kapoor N, Narayana Y, Patil SA, Balaji KN (2010) Nitric oxide is involved in Mycobacterium bovis bacillus Calmette-Guerin-activated Jagged1 and Notch1 signaling. J Immunol 184: 3117-3126.

37. Park JH, Kim HJ, Choy HE, Kim K (2005) Presence of presenilin 1/2 affects the invasion and replication of Salmonella typhimurium. Biochem Biophys Res Commun 332: 1081-1085.

38. Zhou Q Amar S (2007) Identification of signaling pathways in macrophage exposed to Porphyromonas gingivalis or to its purified cell wall components. J Immunol 179: 7777-7790.

39. Otte JM, Podolsky DK (2004) Functional modulation of enterocytes by grampositive and gram-negative microorganisms. Am J Physiol Gastrointest Liver Physiol 286: G613-G626.

40. Caballero-Franco G, Keller K, De SC, Chadee K (2007) The VSL\#3 probiotic formula induces mucin gene expression and secretion in colonic epithelial cells. Am J Physiol Gastrointest Liver Physiol 292: G315-G322.

41. Kim Y, Kim SH, Whang KY, Kim YJ, Oh S (2008) Inhibition of Escherichia coli O157: $\mathrm{H} 7$ attachment by interactions between lactic acid bacteria and intestinal epithelial cells. J Microbiol Biotechnol 18: 1278-1285.

42. Mack DR, Ahrne S, Hyde L, Wei S, Hollingsworth MA (2003) Extracellular MUC3 mucin secretion follows adherence of Lactobacillus strains to intestinal epithelial cells in vitro. Gut 52: 827-833.

43. Croix JA, Bhatia S, Gaskins HR (2011) Inflammatory cues modulate the expression of secretory product genes, Golgi sulfotransferases and sulfomucin production in LS174T cells. Exp Biol Med (Maywood) 236: 1402-1412.

44. Fahlgren A, Hammarstrom S, Danielsson A, Hammarstrom ML (2003) Increased expression of antimicrobial peptides and lysozyme in colonic epithelial cells of patients with ulcerative colitis. Clin Exp Immunol 131: 90-101.

45. Gersemann M, Wehkamp J, Stange E (2011) Innate immune dysfunction in inflammatory bowel disease. J Intern Med 271: 421-428.

46. Sellon RK, Tonkonogy S, Schultz M, Dieleman LA, Grenther W, et al. (1998) Resident enteric bacteria are necessary for development of spontaneous colitis and immune system activation in interleukin-10-deficient mice. Infect Immun 66: 5224-5231.

47. D’Haens G, Geboes K, Peeters M, Baert F, Penninckx F, et al. (1998) Early lesions of recurrent Crohn's disease caused by infusion of intestinal contents in excluded ileum. Gastroenterology 114: 262-267.

48. Wehkamp J, Harder J, Weichenthal M, Schwab M, Schaffeler E, et al. (2004) NOD2 (CARD15) mutations in Crohn's disease are associated with diminished mucosal alpha-defensin expression. Gut 53: 1658-1664.

49. Hugot J-P, Chamaillard C, Zouali H, Lesage S, Cezard J-P, et al. (2001) Association of NOD2 leucine-rich repeat variants with susceptibility to Crohn's disease. Nature 411: 599-603.
50. Henckaerts L, Pierik M, Joossens M, Ferrante M, Rutgeerts P, et al. (2007) Mutations in pattern recognition receptor genes modulate seroreactivity to microbial antigens in patients with inflammatory bowel disease. Gut 56: 15361542 .

51. Cario E (2010) Toll-like receptors in inflammatory bowel diseases: a decade later. Inflamm Bowel Dis 16: 1583-1597.

52. Lucke K, Miehlke S, Jacobs E, Schuppler M (2006) Prevalence of Bacteroides and Prevotella spp. in ulcerative colitis. J Med Microbiol 55: 617-624.

53. Gophna U, Sommerfeld K, Gophna S, Doolittle WF, Veldhuyzen van Zanten SJ (2006) Differences between tissue-associated intestinal microfloras of patients with Crohn's disease and ulcerative colitis. J Clin Microbiol 44: 4136-4141

54. Fyderek K, Strus M, Kowalska-Duplaga K, Gosiewski T, Wedrychowicz A, et al. (2009) Mucosal bacterial microflora and mucus layer thickness in adolescents with inflammatory bowel disease. World J Gastroenterol 15: 5287-5294.

55. Obata Y, Takahashi D, Ebisawa M, Kakiguchi K, Yonemura S, et al. (2012) Epithelial cell-intrinsic notch signaling plays an essential role in the maintenance of gut immune homeostasis. J Immunol 188: 2427-2436.

56. Marteau P, Chaput U (2011) Bacteria as trigger for chronic gastrointestinal disorders. Dig Dis 29: 166-171.

57. Cover TL, Blaser MJ (2009) Helicobacter pylori in health and disease. Gastroenterology 136: 1863-1873.

58. Biarc J, Nguyen IS, Pini A, Gosse F, Richert S, et al. (2004) Carcinogenic properties of proteins with pro-inflammatory activity from Streptococcus infantarius (formerly S.bovis). Carcinogenesis 25: 1477-1484.

59. Abdulamir AS, Hafidh RR, Abu BF (2011) The association of Streptococcus bovis/gallolyticus with colorectal tumors: the nature and the underlying mechanisms of its etiological role. J Exp Clin Cancer Res 30: 11.

60. Chen CC, Lin WC, Kong MS, Shi HN, Walker WA, et al. (2011) Oral inoculation of probiotics Lactobacillus acidophilus NCFM suppresses tumour growth both in segmental orthotopic colon cancer and extra-intestinal tissue. Br J Nutr 1-12.

61. Liong MT (2008) Roles of probiotics and prebiotics in colon cancer prevention: Postulated mechanisms and in-vivo evidence. Int J Mol Sci 9: 854-863.

62. Reedijk M, Odorcic S, Zhang H, Chetty R, Tennert C, et al. (2008) Activation of Notch signaling in human colon adenocarcinoma. Int J Oncol 33: 1223-1229.

63. Peignon G, Durand A, Cacheux W, Ayrault O, Terris B, et al. (2011) Complex interplay between beta-catenin signalling and Notch effectors in intestinal tumorigenesis. Gut 60: 166-176.

64. Park ET, Oh HK, Gum JR Jr, Crawley SC, Kakar S, et al. (2006) HATH1 expression in mucinous cancers of the colorectum and related lesions. Clin Cancer Res 12: 5403-5410.

65. Leow CG, Romero MS, Ross S, Polakis P, Gao WQ (2004) Hath1, downregulated in colon adenocarcinomas, inhibits proliferation and tumorigenesis of colon cancer cells. Cancer Res 64: 6050-6057.

66. Evans PM, Liu C (2008) Roles of Krüppel-like factor 4 in normal homeostasis, cancer and stem cells. Acta Biochim Biophys Sin (Shanghai) 40: 554-564.

67. Zhang W, Chen X, Kato Y, Evans PM, Yuan S, et al. (2006) Novel cross talk of Kruppel-like factor 4 and beta-catenin regulates normal intestinal homeostasis and tumor repression. Mol Cell Biol 26: 2055-2064. 